\title{
Post-COVID-19 Infection and Cognitive Deficits: Permanent or Transient?
}

\author{
Marco Orsini ${ }^{1 *}$, Nicolle Nunes ${ }^{2}$, Carlos Henrique Melo Reis ${ }^{2}$, Valéria Camargo Silveira ${ }^{2}$, Acary Souza \\ Bulle Oliveira ${ }^{3}$, Mauricio Santanna Júnior ${ }^{4}$, Antonio Marcos da Silva Catharino ${ }^{2}$, Bruna Velasques ${ }^{5}$, Alair \\ Pedro Ribeiro ${ }^{5}$, Carlos Eduardo Cardoso ${ }^{6}$, Adriana Leico Oda $^{3}$, Leda Magahães de Oliveira ${ }^{3}$, Roberto \\ Dias Batista Pereira ${ }^{3}$ and Marcos RG de Freitas ${ }^{7}$
}

${ }^{1}$ University of Iguaçu and Master's Program in Neurology - University of Vassouras; Iguassu University - UNIG, Brazil

${ }^{2}$ University Iguaçu - UNIG, Brazil

${ }^{3}$ Federal University of São Paulo, Brazil

${ }^{4}$ Federal Institute of Rio de Janeiro, Brazil

${ }^{5}$ IPUB - Federal University of Rio de Janeiro, Brazil

${ }^{6}$ University of Vassouras - RJ, Brazil

${ }^{7}$ Federal University of Rio de Janeiro - UFR, Brazil

*Corresponding author: Marco Orsini, University of Iguaçu and Master's Program in Neurology - University of Vassouras; Iguassu University - UNIG, Brazil.
Received Date: June 17, 2021

Published Date: July 09, 2021

\section{Short communication}

COVID-19 can be defined as an infectious disease caused by the new coronavirus (Sars-Cov2). The main signs responsible for evinced by the patients are fever, myalgia, dyspnea, and disorders of taste and smell. An array of additional disorders, characterize it as a systemic disease. Nasal congestion, memory deficits, headache, conjunctivitis, pharyngitis, diarrhea, dysautonomia and impairment of diverse organs and systems have been reported. These manifestations may be mild and sometimes asymptomatic, but can also result in death $[1,2]$. Varying degrees of injury may be manifest in the peripheral and central nervous systems (CNS). Two routes of entry into the CNS are already known; a hematogenous pathway mediated by ACE2 receptors, and retrograde neuronal retrograde pathways. These neuropathic mechanisms may explain the increased occurrence of stroke, behavioral changes, and anosmia [3,5]. Another effect of COVID-19 is loss of visualperceptive ability. This reflects injury of the occipital and parietal lobes, which are responsible for executive planning, elements of visual perception, visual-constructive organization and memory.
Many researchers have characterized these cognitive deficits and recent memory loss as a kind of immune-mediated encephalitis [6,7]. Survivors of COVID-19 should be periodically assessed with cognitive and neuropsychiatric tests, and offered cognitive and behavioral rehabilitation programs if necessary. Sars-Cov2 seems to present tropism for the hippocampus, increasing the likelihood of damage making them vulnerable, increasing the probability of monthly damage and, in some cases, accelerating the natural history of neurodegenerative conditions such as Alzheimer's disease [8,9]. In an observational series of 58 patients with COVID19, 33\% had dysexecutive syndrome, characterized by inattention and disorientation, with findings of frontotemporal hypoperfusion on magnetic resonance imaging of the brain [10]. At this point in time, new clinical and ancillary test findings present us with an envolving view of the natural history of this disease. Therefore, now It is not possible to list the chronic sequelae that will be faced by COVID-19 survivors. The long-term consequences of this "brain-infection" remain unknown, but they may be associated with disabilities in 
cognitive (memory), executive process, affective, and behavioral domains [11]. Each of these domains can influence an patient's quality of life, autonomy and relationship. Time will tell?

\section{Acknowledgement}

None.

\section{Conflict of Interest}

No conflict of interest.

\section{References}

1. World Health Organization (2019) Report of the WHO-China Joint Mission on Coronavirus Disease 2019 (COVID-19). https://www.who int/docs/default-source/coronaviruse/whochina-joint-mission-oncovid-19-final-report. pdf (acessado em 20/Fev/2020).

2. Wang C, Horby PW, Hayden FG, Gao GF (2020) A novel coronavirus outbreak of global health concern. Lancet 395: 470-473.

3. Wu D, Shu T, Yang X, Song J-X, Zhang M, et al. (2020) Plasma metabolomic and lipidomic alterations associated with COVID-19. medRxiv 2020; 26 abr.

4. Chen T, Wu D, Chen H, Yan W, Yang D, Chen G, et al. (2020) Clinical characteristics of 113 deceased patients with coronavirus disease 2019: retrospective study. BMJ 368: m1091
5. Oxley TJ, Mocco J, Majidi S, Kellner CP, Shoirah H, et al. (2020) Largevessel stroke as a presenting feature of Covid-19 in the young. $\mathrm{N}$ Engl J Med 382: e60.

6. Yong SJ (2021) Persistent Brainstem Dysfunction in Long-COVID: A Hypothesis. ACS Chem Neurosci 12(4): 573-580.

7. Karuppan MKM, Devadoss D, Nair M, Chand HS, Lakshmana MK (2021) SARS-CoV-2 Infection in the Central and Peripheral Nervous SystemAssociated Morbidities and Their Potential Mechanism. Mol Neurobiol 58(6): 2465-2480.

8. Alonso-Lana S, Marquié M, Ruiz A, Boada M (2020) Cognitive and Neuropsychiatric Manifestations of COVID-19 and Effects on Elderly Individuals with Dementia. Front Aging Neurosci 12: 588872.

9. Ritchie K, Chan D, Watermeyer T (2020) The cognitive consequences of the COVID-19 epidemic: collateral damage? Brain Commun 2(2): fcaa069.

10. Helms J, Kremer S, Merdji H, Clere-Jehl R, Schenck M, et al. (2020) Neurologic Features in Severe SARS-CoV-2 Infection. N Engl J Med 382: 2268-2270.

11. Valença AM, Telles LEB, Barros AJS, da Silva AG (2020) COVID-19, neurocognitive disorders, and civil capacity. Braz J Psychiatry: S151644462020005033205 . 